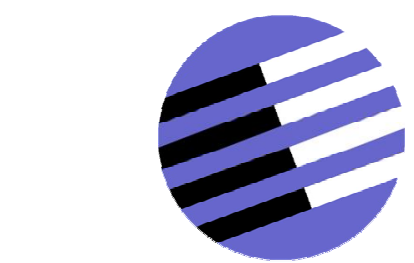

GOVERNANCE AND THE EFFICIENCY

OF ECONOMIC SYSTEMS

G ESY

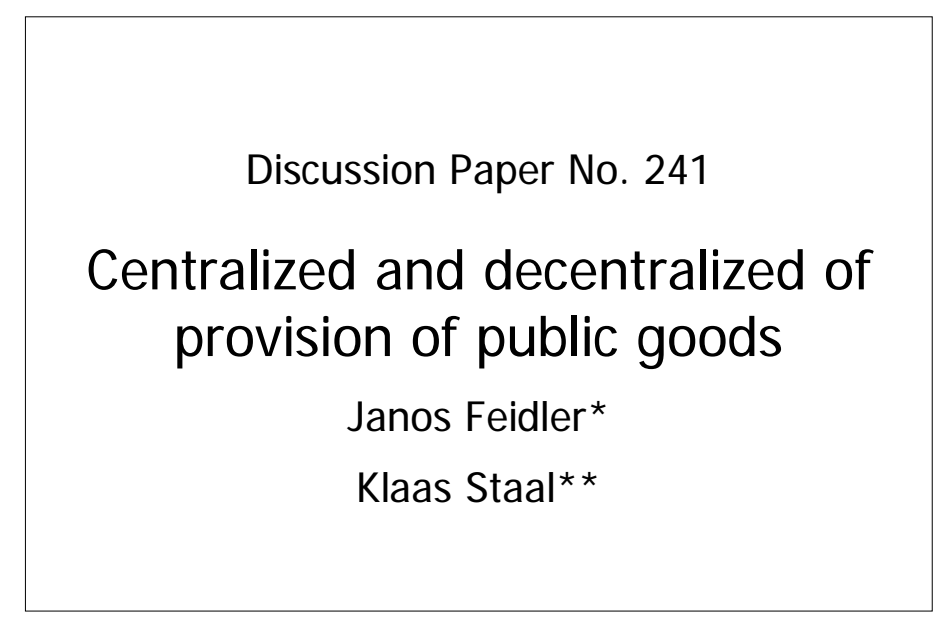

July 2008

*J anos Feidler, University Bonn

**Klaas Staal, University Bonn and IIW, Lennestr. 37, 53113 Bonn, Germany, E-mail: kstaal@uni-bonn.de

Financial support from the Deutsche Forschungsgemeinschaft through SFB/TR 15 is gratefully acknowledged. 


\title{
Centralized and decentralized provision of public goods*
}

\author{
Janos Feidler ${ }^{\dagger}$ and Klaas Staal ${ }^{\ddagger}$
}

July 3, 2008

\begin{abstract}
We model the trade-off between centralized and decentralized decision making over the provision of local public goods. Centralized decisions are made in a legislature of locally elected representatives, and this creates a conflict of interest between citizens in different jurisdictions. The legislature can be self-interested or benevolent and this can result in either efficient, excessive or misallocative provision of public goods. Decisions are influenced by spillover effects and differences in jurisdictional size. Furthermore, we look at the incentives for centralization.
\end{abstract}

Key Words: Decentralization; Local public goods.

JEL Numbers: H40, H70, P51.

*We are grateful to Michael Evers, Jürgen von Hagen, Philipp Jaeschke and Tymofiy Mylovanov and participants of presentations at the 3rd SFB / TR15 Workshop (Bonn), the BGSE Micro/Finance/Public-Finance Workshop (Bonn) and the EPCS 2008 Meeting (Jena). Financial support from the German Research Foundation through SFB / TR15 is gratefully acknowledged.

${ }^{\dagger}$ University Bonn

${ }^{\ddagger}$ University Bonn and IIW. Address: IIW, Lennestr. 37, 53113 Bonn, Germany. E-mail: kstaal@uni-bonn.de 


\section{Introduction}

Centralization or decentralization of local public good provision is one of the main questions in the public finance literature. In a country with geographically distinct districts of different size, local public goods can be provided and financed by the local governments of districts (decentralization) or provided and financed by a central government (centralization). The citizens in a district benefit from the local public goods provided in their district, but also from a positive spillover effect from the goods provided in the other districts. This paper studies whether centralization of decision making and which way of centralized decision making is desirable from a social welfare perspective and whether citizens actually prefer centralization.

Oates (1972) started with the (now) standard approach that each government maximizes the aggregate surplus of its citizens. Under decentralized decision making, this maximization is done separately for each district, while under centralized decision making this is done with a uniform public good level for each district. On the one hand, with decentralization the spillover effects are not taken into account and thus, there is underprovision. On the other hand, however, with centralization the uniform level does not take the differences between districts into account properly. When there are no spillover effects, Oates' Decentralization Theorem says that decentralization is desirable from a social welfare perspective. When there are spillovers, however, centralization can be desirable depending on the differences between the districts and the size of the spillover effect.

Besley and Coate (2003) wrote one of the first papers in which centralization does not imply that uniform levels of public goods have to be provided. They argue that the assumption of uniformity is neither empirically ${ }^{1}$ nor theoretically satisfactory, since there is no convincing theoretical reason that a central government could not provide different levels in districts. Therefore, they use the citizen-candidate approach ${ }^{2}$ to model centralization as decision making in a legislature of locally elected representatives that are self-interested, arguing that this is typically the case in centralized decision making.

\footnotetext{
${ }^{1}$ Examples they give are federal highway spending in the U.S.A. -see Knight (2002), federal spending on river and harbor projects by the Army Corps of engineers -see Ferejohn (1974)- and federal spending on parks by the Department of the Interior. In these examples, federal spending is unequal for each district/state.

${ }^{2}$ See Osborne and Slivinski (1996), Besley and Coate (1997) and Coate (1997).
} 
In the legislature, the representatives of each district have to make a joint decision on the levels of local public goods, given the different preferences in each district for the levels as well as the allocation of the public goods. Besley and Coate look at two specifications of centralized decision making in the legislature. In the first one, a minimum winning coalition ${ }^{3}$ is formed in the legislature and representatives in this coalition make the decision according to their own preferences. This leads to misallocation as well as uncertainty in public good provision, since more public goods are provided to the districts whose representatives are in the coalition, while citizens of a district are unsure whether their representative will be in the minimum winning coalition. In the second specification, there is a cooperative legislature, in which the representatives maximize their joint surplus. This can lead to strategic delegation, since citizens of each district may elect representatives who demand a high level of public goods for their district.

A major contribution of our paper is to model a benevolent legislature that maximizes the aggregate surplus of its citizens, but that is not restricted to a uniform level of public goods under centralized decision making. This is in sharp contrast to Besley and Coate (2003) where the self-interested legislature does not maximize the aggregate surplus of its citizens, but of its representatives. The latter implies a departure from the standard approach by not only dropping the assumption of uniform levels under centralization, but also changing the objective of the legislature. Our approach, as opposed to the others, implies that under centralized decision making the socially optimal levels of public goods are provided.

Another major contribution of our paper is the study of the incentives citizens have for centralizing decision making. We find that, even though centralization leads to a bigger aggregate surplus, individuals in one of the districts might reject centralization since their payoff would decrease, even though the gain in the other district would outweigh this loss. Furthermore, we find that in the approach where centralized decision making obtains the socially optimal levels of public goods, centralization of public good provision is less likely to take place than under other approaches.

Our paper is thus closely related to Besley and Coate (2003). In their approach, individuals within as well as across districts have different preferences over public good provision, while in our paper the key difference is

\footnotetext{
${ }^{3}$ See Buchanan and Tullock (1962), Riker (1962), Ferejohn, Morris and McKelvey (1987) and Baron and Ferejohn (1989).
} 
district size. A comparison of the results implies that the difference in district size is only an imperfect proxy for differences in preferences. For example, when there are only differences across districts, strategic delegation does not take place. Another related paper is Lockwood (2002), but in his approach districts are of the same size, and local public good provision is discrete.

Our research also relates to papers that consider the choice between centralization and decentralization, such as Alesina and Spolaore (1997, 2003), Goyal and Staal (2004) and Bolton and Roland (1997). Other papers also endogenize the decision for centralization, such as Bolton, Roland and Spolaore (1996), Dur and Staal (2008) and Ellingsen (1998), and look at districts of different size, but only in cases in which the large district dominates decision making after centralization.

The rest of the paper is organized as follows. In Section 2 we specify the payoffs. Section 3 presents the socially optimal outcome, while Section 4 presents the outcome under the standard approach. Section 5 discusses the approach introduced by Besley and Coate (2003) and in Section 6 we introduce our approach in which a benevolent legislature makes decisions on public good provision. In Section 7 we conclude with some more general remarks.

\section{The public good}

Assume that a country is divided into two geographically distinct districts. Each district has a continuum of individuals, the districts $i \in\{1,2\}$ have a population size $N_{1}$ and $N_{2}$, with $N_{1}+N_{2}=2$, and without loss of generality, we assume that $N_{1} \leq N_{2}$. In each district, an amount $g_{i}$ of the public good is provided and the payoff an individual in district $i$ gets from these public goods is given by

$$
(1-\kappa) \ln \left(g_{i}\right)+\kappa \ln \left(g_{-i}\right),
$$

where the parameter $\kappa \in[0,1 / 2]$ denotes the spillover effect. The higher $\kappa$, the higher the payoff individuals get from the public goods provided in the other districts. When $\kappa=0$, individuals do not benefit from the public goods provided in the other district, while when $\kappa=1 / 2$, individuals get the same benefit from a unit of public good provided in the other district.

Each individual is endowed with a single private good $x$ and the production of the public goods $g_{1}$ and $g_{2}$ requires $p g_{1}$ and $p g_{2}$ units of the private good. In the following, we look at centralized and decentralized decision 
making over the level of public good provision. Under centralized decision making, the costs of public good provision is borne by the individuals in both districts, so an individual's payoff is given by

$$
(1-\kappa) \ln \left(g_{i}\right)+\kappa \ln \left(g_{-i}\right)+x-\frac{p\left(g_{i}+g_{-i}\right)}{2} .
$$

Under decentralized decision making, individuals in each district have to bear the costs of public good provision in their own district and an individual has a payoff of

$$
(1-\kappa) \ln \left(g_{i}\right)+\kappa \ln \left(g_{-i}\right)+x-\frac{p g_{i}}{N_{i}} .
$$

Finally, in the following we also look at the individual incentives for centralization of decision making. There is a referendum in each district and each individual can choose between centralization or decentralization. Centralization only takes place when majorities in both districts prefer centralized over decentralized decision making.

\section{The social optimum}

We use the socially optimal outcome as a benchmark for comparing the results under centralized and decentralized decision making. We furthermore use social surplus to compare whether centralization of decision making is desirable, from a social welfare point of view. When $g_{1}$ and $g_{2}$ are the provided levels of public goods, the social surplus is given by

$$
\left[N_{1}(1-\kappa)+N_{2} \kappa\right] \ln \left(g_{1}\right)+\left[N_{1} \kappa+N_{2}(1-\kappa)\right] \ln \left(g_{2}\right)-p\left(g_{1}+g_{2}\right) .
$$

The social optimum is given by the public good levels $\hat{g}_{1}$ and $\hat{g_{2}}$ that maximizes the aggregate public good surplus:

$$
\begin{gathered}
\left(\hat{g_{1}}, \hat{g_{2}}\right)=\arg \max _{g_{1}, g_{2}}= \\
{\left[N_{1}(1-\kappa)+N_{2} \kappa\right] \ln \left(g_{1}\right)+\left[N_{1} \kappa+N_{2}(1-\kappa)\right] \ln \left(g_{2}\right)-p\left(g_{1}+g_{2}\right) .}
\end{gathered}
$$


The public good levels that maximize aggregate public good surplus are calculated by taking first-order conditions and solving. This yields:

$$
\left(\hat{g_{1}}, \hat{g_{2}}\right)=\left(\frac{N_{1}(1-\kappa)+N_{2} \kappa}{p}, \frac{N_{1} \kappa+N_{2}(1-\kappa)}{p}\right) .
$$

Note that when $N_{1}$ exceeds $N_{2}$, district 1's level is higher for all $\kappa<1 / 2$.

\section{The standard approach}

In the standard approach, following Oates (1972), a government maximizes the aggregate public good surplus of its citizens. We look consecutively at decentralized and centralized decision making. Under decentralized decision making, each district has its own government, while under centralized decision making a single government represents both districts. The section ends with a comparison of centralized and decentralized decision making.

Decentralized decision making In a decentralized system each district's government chooses independently the district's local public good level. The government's objective is to maximize local public good surplus in its own district. Note that the chosen public good levels $\left(g_{1}^{d}, g_{2}^{d}\right)$ form a Nash equilibrium. This implies that these public good levels are given by the following maximization problem:

$$
g_{i}^{d}=\arg \max _{g_{i}}\left\{(1-\kappa) \ln \left(g_{i}\right)+\kappa \ln \left(g_{-i}\right)-\frac{p g_{i}}{N_{i}}\right\} .
$$

The public good levels under decentralized decision making are calculated by taking first-order conditions and solving. This yields:

$$
\left(g_{1}^{d}, g_{2}^{d}\right)=\left(\frac{(1-\kappa) N_{1}}{p}, \frac{(1-\kappa) N_{2}}{p}\right) .
$$

While each government maximizes the surplus of its own citizens, the local public good levels under non-cooperative decentralized decision making are only surplus-maximizing when there is no spillover effect. When there is a spillover effect, there is underprovision of public goods in both districts, and this underprovision becomes more severe when the spillover effect increases. 
Centralized decision making In a centralized system, a uniform level of the public good is provided by assumption in each district. The government's objective is to maximize the aggregate local public good surplus of the citizens in both districts. This implies that the amount of public goods is given by the following maximization problem:

$$
g_{1}^{c}=g_{2}^{c}=\arg \max _{g}\{2 \ln (g)-2 p g\} .
$$

The public good levels under standard centralized decision making are calculated by taking first-order conditions and solving. This yields:

$$
g_{1}^{c}=g_{2}^{c}=\frac{1}{p} .
$$

Note that the level of local public goods does not depend on the size of the spillover effect. It only equals the socially optimal levels when the spillover effect is perfect (i.e. $\kappa=1 / 2$ ) or when both districts have the same size. When the spillover effect is imperfect, there is overprovision in the small district but underprovision in the big district.

Comparison We first examine whether centralization of decision making is desirable from a social welfare perspective. To do so, we subtract the aggregate surplus under decentralized decision making -(3) with (6)- from the surplus under centralization -(3) with (8)-.

$$
\left(N_{i}(1-\kappa)+N_{-i} \kappa\right) \ln \left((1-\kappa) N_{i}\right)-\left(N_{i} \kappa+N_{-i}(1-\kappa)\right) \ln \left((1-\kappa) N_{-i}\right)-2 \kappa
$$

Centralization is thus desirable when the above difference is positive.

Note that from the results above it follows that under decentralized decision making the socially optimal levels of local public goods are provided when there is no spillover effect. When the spillover effect is perfect, however, socially optimal levels are provided under centralized decision making. Finally, the underprovision of local public goods under decentralized decision making increases with the size of the spillover effect, while local public good levels under centralized decision making do not depend on the size of the spillover effect. These observations imply the following.

Proposition 1 Under the standard approach, decentralized decision making leads to a higher local public good surplus when there is no spillover effect. 
There is a value of the spillover effect such that both centralized and decentralized decision making create the same surplus, while with perfect spillovers centralized decision making leads to a higher surplus.

Note that this proposition is in line with Oates' Decentralization Theorem - in the absence of spillovers, decentralized decision making is optimal. An illustration of the social incentives for centralization is given in Figure 1.

Now look at an individual's preferences over centralization of decision making. Subtracting the payoff under decentralization -(2) with (6)- from the payoff under centralization -(1) with (8)- gives the incentives of an individual to choose centralization:

$$
-(1-\kappa) \ln \left((1-\kappa) N_{i}\right)-\kappa \ln \left((1-\kappa) N_{-i}\right)-\kappa .
$$

The individuals in district $i$ thus prefer centralization over decentralization if this is positive. When $0<N_{i} \leq 1$ then (10) decreases with increasing $N_{i}$ for all $0 \leq \kappa \leq \frac{1}{2}$ and for $N_{i}=1$ it is positive for all possible values of $\kappa$. The individuals in district 1 thus always prefer centralization of decision making. For $1<N_{i} \leq 2$, however, (10) is negative when $\kappa=0$ and positive for $\kappa=\frac{1}{2}$. Individuals in district 2 thus only prefer centralization when the spillover effect is big enough. This implies the following.

Proposition 2 Under the standard approach, centralization only takes place when the spillover effect exceeds a certain threshold value.

An illustration of these incentives for centralizing decision making is given in Figure 1.

We now compare the incentives for centralization under majority voting with the socially optimal incentives. To do so, we compare the pairs of $N_{i}$ and $\kappa$ for which (9) and (10) are positive. To make such a comparison insightful, we have calculated for a thousand values of $N_{2}$ the values of $\kappa$ for which (9) and (10) are equal to zero. These values can be found in Figure 1, and this illustrates the following result.

Proposition 3 From a social welfare perspective, individuals have insuffcient incentives to centralize decision making.

There is an obvious explanation for these insufficient incentives. Under decentralized decision making, all individuals within each district obtain the same payoff, say $\hat{S}_{1}$ and $\hat{S_{2}}$, respectively, and total surplus then is $N_{1} \hat{S}_{1}+N_{2} \hat{S}_{2}$. 
Centralization only takes place if the payoffs for both districts increase. However, when centralization only makes one payoff higher and the other payoff (only a bit) smaller, the latter individuals will reject centralization even though centralization could increase aggregate social welfare.

We see in Figure 1 that for small values of the spillover effect, centralization is neither the majority voting outcome nor socially desirable. From a social welfare perspective, for small spillover effects it is better to have public good levels that depend on district size, even though there might be underprovision in the small district. For higher spillover effects, however, the underprovision becomes so severe that centralization does better, even though under centralization uniform levels have to be provided in both districts. Under majority voting, nevertheless, individuals in the largest districts are even more reluctant to centralization, since under centralized decision making they partly have to bear the costs of the public goods provided in the smaller district.

Some assumptions underlying the standard approach influence the results significantly. One is that a government chooses public good levels to maximize aggregate public good surplus, and another is that under centralized decision making uniform levels of public goods have to be provided. In Section 5, we introduce elections of individuals representing the government, and these individuals choose public good levels to maximize their own surplus. This alters the first assumption, while we also drop the assumption of uniformity under centralized decision making. In Section 6, public good levels also do not need to be uniform under centralized decision making, and again there are elections of individuals representing the government. These individuals, however, maximize aggregate public good surplus, thus restoring the first-mentioned assumption.

\section{A self-interested legislature}

In this section we introduce elections to the model, using the citizen-candidate approach. In this approach, elections are organized to select an individual for a legislature (government). Elected individuals are assumed to base their decisions on their own self-interest, and a voter therefore tries to select a candidate whose self-interest is in line with the voter's interest. We first look at decentralized decision making and then at centralized decision making with a self-interested legislature. The section ends with a comparison 
of both forms of decision making.

Decentralized decision making With decentralized decision making in self-interested legislatures, individuals in each district elect a single representative from the district who then determines its policy. First, simultaneous elections thus make place in each district to determine which individuals (i.e. citizens) represent a district. Second, the two elected individuals simultaneously but separately determine the levels of public goods in each district. We solve this game by backward induction. The two elected individuals of district $i \in\{1,2\}$ face the following maximization problem:

$$
g_{i}^{d}=\arg \max _{g_{i}}\left\{(1-\kappa) \ln \left(g_{i}\right)+\kappa \ln \left(g_{-i}\right)-\frac{p g_{i}}{N_{i}}\right\} .
$$

The public good levels under decentralized decision making are calculated by taking first-order conditions and solving. This yields:

$$
\left(g_{1}^{d}, g_{2}^{d}\right)=\left(\frac{(1-\kappa) N_{1}}{p}, \frac{(1-\kappa) N_{2}}{p}\right) .
$$

Note that in a district all citizens have the same preferences. Accordingly, the levels of public goods do not depend on which citizens are elected, and the local public good levels $\left(g_{1}^{d}, g_{2}^{d}\right)$ are thus given by expression (12). Furthermore, it follows that decentralized decision making with self-interested legislatures yields the same outcome as in the standard approach.

Centralized decision making With centralized decision making in a selfinterested legislature, individuals in each district elect a single representative in a legislature, while the representatives in the legislature make decisions on the levels of public goods in each district. First, simultaneous elections thus take place in each district to determine which individuals (i.e. citizens) represent the district in the legislature. Each district is thus represented by one individual from the district. Second, the legislature determines the levels of the public goods. We solve this game by backward induction.

For this solution it is important how the levels of public goods are determined in the legislature. We use the minimum winning coalition view to model a noncooperative decision process in the legislature, while we also look at a cooperative decision process in which the representatives in the 
legislature maximize their joint surplus.

Under the minimum winning coalition view, a coalition that forms a majority of the representatives determines public good levels. When $N_{1}<N_{2}$, one could argue that the representative of district 2 invariably forms the winning coalition in the legislature. The decisions of the legislature would then only reflect the preferences of district 2's representative. The level of public goods provided in district 2 is optimal for the citizens of district 2 , while the level of public goods in district 1 is only determined by the spillover effect for the individuals in district 2 .

However, we do not only evaluate the outcomes in which the representative of district 2 forms the minimum winning with certainty, but also the possibility that the representative of each district forms the winning coalition with a probability proportional to his district's population size as well as the possibility that both representatives are in the minimum winning coalition with equal probability.

Finally, we also look at cooperative decision making in the legislature. In this case, the representatives in the legislature choose a utilitarian bargaining solution, maximizing joint surplus.

In a noncooperative legislature and when the representative from district $i$ forms the minimum winning coalition, this representative faces the following maximization problem:

$$
\left(g_{i}^{c}, g_{-i}^{c}\right)=\arg \max _{\left(g_{i}, g_{-i}\right)}\left\{(1-\kappa) \ln \left(g_{i}\right)+\kappa \ln \left(g_{-i}\right)-\frac{p\left(g_{i}+g_{-i}\right)}{2}\right\} .
$$

The public good levels under decentralized decision making are calculated by taking first-order conditions and solving. This yields:

$$
\left(g_{i}^{c}, g_{-i}^{c}\right)=\left(\frac{2(1-\kappa)}{p}, \frac{2 \kappa}{p}\right) .
$$

Note that in a district all citizens have the same preferences. Accordingly, the levels of public goods do not depend on which citizens are elected, and the local public good levels are thus given by expression (14).

For an evaluation of the outcomes, however, it is important which individual forms the minimum winning coalition. The district whose representative is in the minimum winning coalition has an advantage in the sense that more public goods are provided in this district, while less public goods are provided 
in the other district. Except when spillovers are perfect, there thus is misallocation in public good provision. More public goods than the socially optimal amount are provided in the district whose representative forms the minimum winning coalition, while less public goods than optimal are provided in the other district.

Unless the biggest district dominates decision making, such that its representative always forms the minimum winning coalition, there is also uncertainty in public good provision. Since it is not clear beforehand whether a representative is in the minimum winning coalition, it is also unclear where the highest level of the public good is provided.

Finally, note that the public good levels are only equal to the socially optimal levels when the spillover effect is perfect.

In a cooperative legislature, both representatives face the following maximization problem for the joint surplus.

$$
\left(g_{1}^{c}, g_{2}^{c}\right)=\arg \max _{\left(g_{1}, g_{2}\right)} \sum_{i \in\{1,2\}}\left\{(1-\kappa) \ln \left(g_{i}\right)+\kappa \ln \left(g_{-i}\right)-\frac{p\left(g_{i}+g_{-i}\right)}{2}\right\} .
$$

The public good levels chosen by a cooperative legislature are calculated by taking first-order conditions and solving. This yields:

$$
\left(g_{1}^{c}, g_{2}^{c}\right)=\left(\frac{1}{p}, \frac{1}{p}\right)
$$

Note that in a district all citizens have the same preferences. Accordingly, the levels of public goods do not depend on which citizens are elected, and the local public good levels are thus given by expression (16). Furthermore, it follows that centralized decision making with self-interested legislatures yields the same outcome as in the standard approach.

Comparison Several comparisons can be made. We first compare decentralization with noncooperative as well as cooperative centralization and then cooperative with noncooperative centralization. Furthermore, we look at the incentives individuals have for centralization.

As in the standard approach, under decentralized decision making each government maximizes the surplus of its own citizens and the local public good levels are only surplus-maximizing when there is no spillover effect. 
When there is a spillover effect, there is underprovision of public goods in both districts, and this underprovision becomes more severe when the spillover effect increases. With noncooperative as well as cooperative centralized decision making, the public good levels are only socially optimal when the spillover effect is perfect. These observations are reflected in the following proposition:

Proposition 4 With self-interested legislatures, for noncooperative as well as cooperative centralization, it holds that decentralized decision making leads to a higher public good surplus when there is no spillover effect. There is a value of the spillover effect such that both centralized and decentralized decision making create the same surplus, while with perfect spillovers centralized decision making leads to a higher surplus.

Note that this comparison is qualitatively the same as the comparison made for the standard approach and that it is thus also in line with Oates' Decentralization Theorem - in the absence of spillovers, decentralized decision making is optimal. The proof of Proposition 4 is in the appendix.

With self-interested legislatures, the public good levels with decentralized as well as with cooperative centralized decision making are the same as the levels under the standard approach. The comparison of decentralized and cooperative centralized decision making is thus analogous to the comparison presented in Section 4. From the discussion in this section it also follows that under cooperative as well as noncooperative centralized decision making individuals have fewer incentives for centralization than socially desirable.

Now we turn to individual incentives for noncooperative centralization. These incentives depend on the expected public good surplus under centralization and thus depend on which representative forms the minimum winning coalition under centralization. Let $\operatorname{Pr}[i]$ denote the probability that the representative of district $i$ forms the minimum winning coalition. Then the expected public good surplus of an individual in district $i$ under centralization is

$$
\operatorname{Pr}[i]\left\{(1-\kappa) \ln \left(g_{i}\right)+\kappa \ln \left(g_{-i}\right)\right\}+\operatorname{Pr}[-i]\left\{(1-\kappa) \ln \left(g_{-i}\right)+\kappa \ln \left(g_{i}\right)\right\}-1
$$

with $\left(g_{i}, g_{-i}\right)$ given by $(14)$. The public good surplus of an individual in 
district $i$ under decentralized decision making is

$$
(1-\kappa) \ln \left(\frac{(1-\kappa) N_{i}}{p}\right)+\kappa \ln \left(\frac{(1-\kappa) N_{-i}}{p}\right)-(1-\kappa)
$$

and an individual prefers centralization when (17) is larger than (18). The individual incentives for cooperative centralization are given by subtracting the payoff under decentralization -(2) with (12)- from the payoff under centralization -(1) with (16)-. The following result is based on the above differences.

Proposition 5 With a self-interested legislature, individuals only choose to centralize (cooperative or noncooperative) decision making when the spillover effect exceeds a certain threshold value.

The proof of Proposition 5 is in the appendix.

We now take a look at the individual incentives for noncooperative centralization. For such a comparison we should compare the pairs of $N_{i}$ and $\kappa$ for which the social surplus and the difference of (17) and (18) are positive for the three different approaches to forming a minimum winning coalition. To make this insightful we have calculated the values of $\kappa$ for a thousand values of $N_{2}$, for which the social surplus and these differences are equal to zero. These values can be found in Figure 2. It follows that when the districts do not differ much in size -when $N_{2}$ is close to 1 - the incentives for centralization do not differ much when the minimum winning coalition is formed by the larger district either with probability $\frac{1}{2}$ or with a probability equal to $\frac{N_{2}}{2}$. Clearly, this is due to the fact that the latter two probabilities are almost the same. When the larger district forms the minimum winning coalition with probability 1 , however, individuals in the smaller district are less likely to prefer centralization and centralization only occurs for larger values of the spillover effect.

When there is a bigger difference in size between both districts, centralization is most likely to take place when the larger district is in the minimum winning coalition with probability 1 . In this case, the individuals always prefer centralization since they dominate centralized decision making and are thus able to set public good levels to their own preferences. Moreover, the small district is so small that its individuals benefit from centralization in most cases, even though decisions are then made according to the preferences of individuals in the big district. When both districts are in the minimum 
winning coalition with equal probability, the individuals in the small district prefer centralization in more cases. The individuals in the large district, however, are less likely to prefer centralization since it makes it possible that public good levels are set according to the preferences of the individuals in the small district.

In the approach that we discus in this section, representatives in the legislature choose public good levels that maximize their own payoff. In the standard approach, however, public good levels are chosen to maximize the aggregate surplus of all the individuals. In the next section, we therefore change the objective of the legislature. Instead of self-interest, we then assume that representatives in the legislature are benevolent in the sense that they choose to maximize an aggregate surplus, as is assumed in the standard approach.

\section{A benevolent legislature}

In Section 5 we introduced elections in the decision making over the levels of public goods. Public good provision was no longer uniform across districts, as it is in the standard approach, and at the same time, the benevolent surplusmaximizing legislature was changed into representatives making decisions based on self-interest. In this section we introduce a new approach of decision making, in which, as in the approach with a self-interested legislature, public good provision need not be uniform across districts, but the legislature is assumed to be benevolent, that is to maximize surplus. We first look at decentralized decision making and then at centralized decision making in this benevolent-legislature approach. The section ends with a comparison of both forms of decision making.

Decentralized decision making Under the benevolent-legislature approach and with decentralized decision making, individuals in each district elect a single representative from the district who then determines its policy. First, simultaneous elections thus take place in each district to determine which individuals (i.e. citizen) represent a district. Second, the two elected individuals simultaneously but separately determine the levels of public goods in each district. These levels maximize the aggregate surplus in each district. We solve this game by backward induction. The two elected individuals of 
district $i \in\{1,2\}$ face the following maximization problem:

$$
g_{i}^{d}=\arg \max _{g_{i}}\left\{N_{i}\left[(1-\kappa) \ln \left(g_{i}\right)+\kappa \ln \left(g_{-i}\right)\right]-p g_{i}\right\} .
$$

The public good levels under decentralized decision making are calculated by taking first-order conditions and solving. This yields:

$$
\left(g_{1}^{d}, g_{2}^{d}\right)=\left(\frac{(1-\kappa) N_{1}}{p}, \frac{(1-\kappa) N_{2}}{p}\right) .
$$

Since in a district all citizens have the same preferences, the levels of public goods do not depend on which citizens are elected, and the local public good levels are thus indeed given by expression (20). A comparison of expressions (6), (12) and (20) reveals that, under decentralized decision making, the outcomes with a benevolent legislature are the same as with a self-interested legislature and in the standard approach.

Centralized decision making Under the benevolent-legislature approach and with centralized decision making, individuals in each district elect a single representative in a legislature, while the representatives in the legislature make decisions on the levels of public goods in each district. First, simultaneous elections take place in each district to determine which individuals (i.e. citizens) represent the district in the legislature. Second, the legislature determines the levels of the public goods. The representatives in the legislature choose these levels such that the levels maximize the aggregate surplus of both districts, given the preferences revealed in the first stage. We solve this game by backward induction. The representatives thus face the following maximization problem:

$$
\left(g_{i}^{c}, g_{-i}^{c}\right)=\arg \max _{\left(g_{i}, g_{-i}\right)} \sum_{i \in\{1,2\}}\left\{N_{i}\left[(1-\kappa) \ln \left(g_{i}\right)+\kappa \ln \left(g_{-i}\right)\right]-N_{i} \frac{p\left(g_{i}+g_{-i}\right)}{2}\right\}
$$

The public good levels under centralized decision making are calculated by taking first-order conditions and solving. This yields:

$$
\left(g_{1}^{c}, g_{2}^{c}\right)=\left(\frac{N_{1}(1-\kappa)+N_{2} \kappa}{p}, \frac{N_{1} \kappa+N_{2}(1-\kappa)}{p}\right) .
$$


Note that in a district all citizens have the same preferences. Accordingly, the levels of public goods do not depend on which citizens are elected, and the local public good levels are thus given by expression (22). A comparison of (4) and (22) reveals that centralized decision making by a benevolent legislature leads to the socially optimal levels of public goods.

Comparison From the results above it follows that under centralized decision making, the socially optimal levels are always provided. Under decentralization, the optimal levels are only provided when there is no spillover effect. These observations imply the following proposition.

Proposition 6 With a benevolent legislature, centralized and decentralized decision making leads to the same surplus when there is no spillover effect, while centralized decision making leads to a higher public good surplus when there is a spillover effect.

Again, this is similar to the results obtained for the standard approach and with a benevolent legislature, but in an even more clear-cut way. In the absence of spillover effects, decentralization is optimal -Oates' Decentralization Theorem- while with a benevolent legislature, in all other cases centralized decision making is strictly better.

Now look at the individual preferences over centralization of decision making. Subtracting the payoff under decentralization -(2) with (20)- from the payoff under centralization -(1) with (22)- gives the incentives of an individual for centralization

$$
\begin{gathered}
(1-\kappa) \ln \left((1-\kappa) N_{i}+\kappa N_{-i}\right)+\kappa \ln \left((1-\kappa) N_{-i}+\kappa N_{i}\right)- \\
(1-\kappa) \ln \left((1-\kappa) N_{i}\right)-\kappa \ln \left((1-\kappa) N_{-i}\right)-\kappa
\end{gathered}
$$

The individuals in district $i$ thus prefer centralization over decentralization if this is positive. It is straightforward to show that this difference is positive when both districts have the same size and that district 1, the smaller district, always prefers centralization. For individuals in district 2, the larger district, the difference is always positive when the spillover effect is perfect, that is when $\kappa=\frac{1}{2}$. It is straightforward to show, however, that centralization does not always take place under majority voting when $\kappa<\frac{1}{2}$.

Now compare the individual incentives for centralization under the standard approach with those with a self-interested or a benevolent government. To do so, we have calculated the threshold values of $\kappa$ for a thousand values 
of $N_{2}$, above which centralization takes place under majority voting. This is done for the standard approach, giving the same outcome as with cooperative centralization in a self-interested legislature. For noncooperative centralization with a self-interested legislature, we took the minimum value of $\kappa$ above which centralization takes place. That is, for $N_{2}$ close to 1 we took the $\kappa \mathrm{s}$ when each district is in the minimum winning coalition with a probability proportional to district size, while for bigger values of $N_{2}$ we took the the $\kappa \mathrm{s}$ when the representative from the larger district always forms the minimum winning coalition.

Figure 3 illustrates that when the difference in size between the two districts is small, centralization is most likely the majority voting outcome under the standard approach. When the difference in district size is large, however, centralization is more likely to be the majority voting outcome under noncooperative centralization with a self-interested legislature. From this it follows that, even though centralization with a benevolent legislature would imply socially optimal levels of public goods, it also implies smaller incentives for centralization.

\section{Concluding remarks}

Public economists have extensively researched the centralized versus decentralized provision of local public goods. In the standard approach of Oates (1972), albeit assuming that benevolent governments maximize aggregate welfare of their citizens, centralized provision implies uniform levels of public goods. This uniformity is a disadvantage of centralization since it prevents differences between districts to be reflected in the levels of public goods that are provided.

In the approach of Besley and Coate (2003), citizens choose representatives in legislatures that make decisions on public good provision. The representatives maximize their own surplus, instead of maximizing the aggregate surplus of the citizens. Additionally, the representatives can provide different levels to each district under centralized decision making. This, however, leads to misallocation and uncertainty in public good provision, since centralized decisions are assumed to be made by a minimum winning coalition of representatives in the legislature. The citizens are uncertain whether their representatives will be in this coalition, while the representatives in the coalition make decisions based on their own preferences, ignoring the 
preferences in the other districts.

The approach we propose in this paper deviates in just a single way from the standard approach. Centralized decision making is done by a benevolent legislature that maximizes the aggregate surplus, as in the standard approach, but can provide different public good levels in each district. In contrast to Besley and Coate (2003), socially optimal public good provision takes place under centralization. However, centralization is not always preferred by a majority of the individuals.

The analysis can be extended in several important ways. One way is to loosen the uniform taxation assumption. Another way is introducing transfers into the analysis. Finally, since district size is observable, the analysis opens possibilities for empirical research on, for example, the preferences of districts over centralization, given the different ways the decision-making process is structured after centralization.

\section{A Appendix}

Proof of Proposition 4. First, note that when there is no spillover effect the public good surplus attains the maximum possible value under decentralization, since the public good levels are then socially optimal. This proves the first statement in the proposition. Likewise, when the spillover effect is perfect, with noncooperative as well as cooperative decision making the public good surplus attains the maximum possible value under centralization. This proves the last statement in the proposition.

The aggregate public goods surplus under decentralization is

$$
\begin{gathered}
\left(N_{1}(1-\kappa)+N_{2} \kappa\right) \ln \left(\frac{(1-\kappa) N_{1}}{p}\right)+\left(N_{1} \kappa+N_{2}(1-\kappa)\right) \ln \left(\frac{(1-\kappa) N_{2}}{p}\right) \\
-2(1-\kappa) .
\end{gathered}
$$

The aggregate public good surplus under noncooperative centralization depends on which representative forms the minimum winning coalition. Let $\operatorname{Pr}[i]$ denote the probability that the representative of district $i$ forms the 
minimum winning coalition. The expected value of the surplus then is

$$
\begin{gathered}
\operatorname{Pr}[1]\left[\left(N_{1}(1-\kappa)+N_{2} \kappa\right) \ln \left(\frac{2(1-\kappa)}{p}\right)+\left(N_{1} \kappa+N_{2}(1-\kappa)\right) \ln \left(\frac{2 \kappa}{p}\right)\right]+ \\
\operatorname{Pr}[2]\left[\left(N_{1}(1-\kappa)+N_{2} \kappa\right) \ln \left(\frac{2 \kappa}{p}\right)\left(N_{1} \kappa+N_{2}(1-\kappa)\right) \ln \left(\frac{2(1-\kappa)}{p}\right)\right] \\
-2 .
\end{gathered}
$$

and the aggregate public good surplus under cooperative centralization is

$$
2 \ln \left(\frac{1}{p}\right)-2
$$

Note that the three public good surpluses are continuous in $\kappa$. Together with the two statements mentioned at the beginning of the proof it follows that there exists a value of $\kappa$ such that centralized and decentralized decision making create the same surplus.

\section{Proof of Proposition 5.}

When the minimum winning coalition is formed by the larger district, then the expected gain from centralizing decision making for an individual in district 1 is

$$
-(1-\kappa) \ln \left(\frac{(1-\kappa) N_{1}}{2 \kappa}\right)-\kappa \ln \left(\frac{N_{2}}{2}\right)-\kappa
$$

while the expected gain for an individual in district 2 is

$$
-(1-\kappa) \ln \left(\frac{N_{2}}{2}\right)-\kappa \ln \left(\frac{(1-\kappa) N_{1}}{2 \kappa}\right)-\kappa .
$$

It is straightforward to show that the expected gain for an individual in district 2 is always positive. When $\kappa=0$, the difference for individuals in district 1 is negative, and when $\kappa=1 / 2$, the gain is positive. Since individuals in both districts have to choose to centralize, it follows that centralization only takes place when $\kappa$ exceeds a threshold value.

When the minimum winning coalition is formed by each district with a probability proportional to district size, that is, with probability $N_{1} / 2$ for district 1 and probability $N_{2} / 2$ for district 2, the expected gain from 
centralization is

$$
\begin{gathered}
-(1-\kappa) \ln \left((1-\kappa) N_{i}\right)+\kappa \ln \left((1-\kappa) N_{-i}\right)+ \\
\frac{N_{i}}{2}((1-\kappa) \ln (2 \kappa)+\kappa \ln (2-2 \kappa)) \\
+\frac{N_{-i}}{2}((1-\kappa) \ln (2-2 \kappa)+\kappa \ln (2 \kappa))-\kappa .
\end{gathered}
$$

It is straightforward to show that this gain is always positive for $\kappa=1 / 2$. When $\kappa$ is close enough to 0 , however, this difference is negative, while the gain is increasing in $\kappa$. It thus follows that centralization only takes place when $\kappa$ exceeds a threshold value.

When the minimum winning coalition is formed by each district with equal probability, the expected gain from centralization for an individual in district 1 is

$$
-(1-\kappa) \ln \left((1-\kappa) N_{1}\right)-\kappa \ln \left((1-\kappa) N_{2}\right)+\frac{1}{2} \ln (4 \kappa(1-\kappa))-\kappa
$$

while the expected gain from decentralization for an individual in district 2 is

$$
-(1-\kappa) \ln \left((1-\kappa) N_{2}\right)-\kappa \ln \left((1-\kappa) N_{1}\right)+\frac{1}{2} \ln (4 \kappa(1-\kappa))-\kappa .
$$

For $\kappa=\frac{1}{2}$, the expected gain from centralization is always positive for the individuals in district 1, and this gain is increasing in $\kappa$. For $\kappa=0$, the difference for individuals in district 2 is negative and for $\kappa=\frac{1}{2}$, the gain is positive, while the difference is increasing in $\kappa$. Since individuals in both districts have to prefer centralization to let centralization take place, it follows that centralization only happens when $\kappa$ exceeds a threshold value.

With a cooperative legislature, the analysis is the same as in the standard approach.

\section{References}

[1] Alesina, A., Spolaore, E., 1997. On the number and size of nations. Quarterly Journal of Economics 112, 1027-1056.

[2] Alesina, A., Spolaore, E., 2003. The size of nations. MIT Press, Cambridge, Massachusetts. 
[3] Baron, D., 1991. Majoritarian incentives, pork barrel programs and procedural control. American Journal of Political Science 35 (1), 57-90.

[4] Baron, D., Ferejohn, J., 1989. Bargaining in legislatures. American Political Science Review 83, 1181-1206.

[5] Besley, T., Coate, S., 1997. An economic model of representative democracy. Quarterly Journal of Economics 112 (1), 85-114.

[6] Bolton, P., Roland, G., 1993. The break-up of nations: A political economy analysis. Quarterly Journal of Economics 112, 1057-1089.

[7] Bolton, P., Roland, G., Spolaore, E., 1996. Economic theories of the break-up and integration of nations. European Economic Review 40, 697-705.

[8] Buchanan, J., Tullock, G., 1962. The Calculus of Consent. University of Michigan Press, Ann Arbor.

[9] Dur, R., Staal, K., 2008(Forthcoming). Local public good provision, municipal consolidation, and national transfers. Regional Science and Urban Economics.

[10] Ellingsen, T., 1998. Externalities vs internalities: A model of political integration. Journal of Public Economics 68, 251-268.

[11] Ferejohn, J., 1974. Pork Barrel Politics: Rivers and Harbors Legislation 1947-1968. Stanford University Press, Stanford, CA.

[12] Ferejohn, J., Morris, F., McKelvey, R., 1987. Sophisticated voting and agenda independence in the distributive politics setting. American Journal of Political Science 31, 167-193.

[13] Goyal, S., Staal, K., 2004. The political economy of regionalism. European Economic Review 48, 563-593.

[14] Lockwood, B., 2002. Distributive Politics and the Benefits of Decentralization. Review of Economic Studies 69 (2), 313-338.

[15] Oates, W., 1972. Fiscal Federalism. Harcourt Brace, New York.

[16] Tiebout, C., 1956. A pure theory of local expenditures. Journal of Political Economy 64 (5), 416-424. 


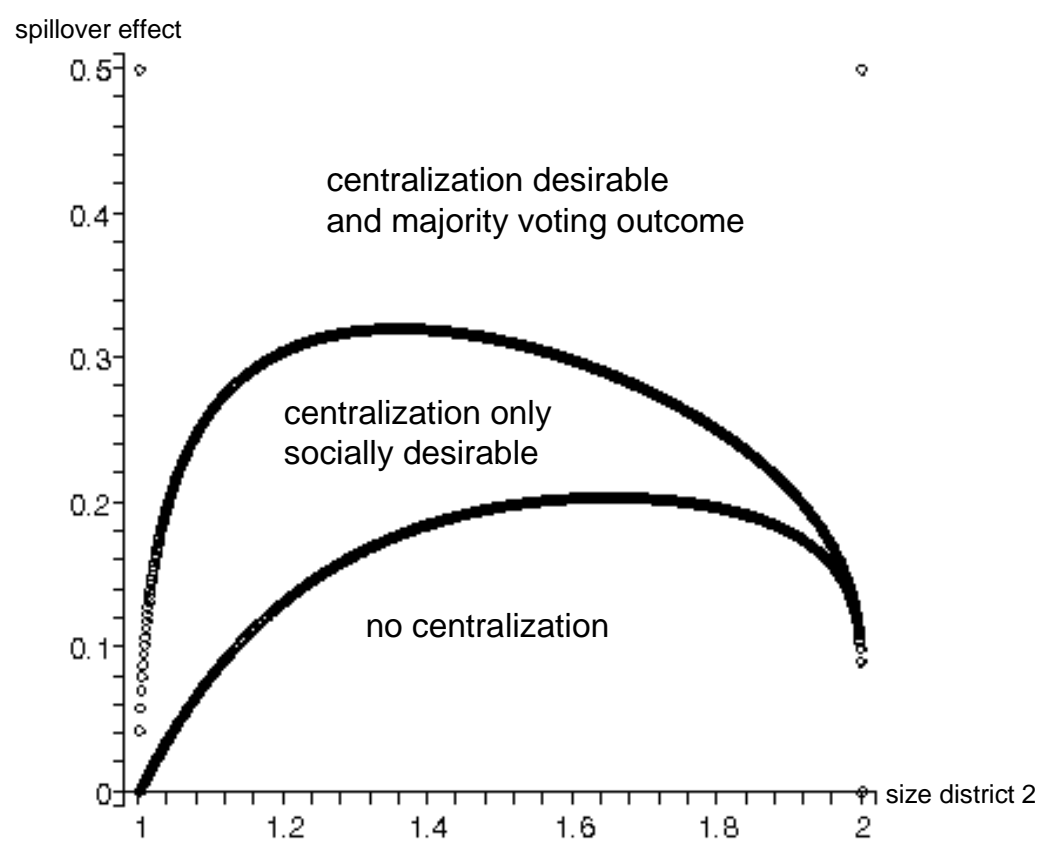

Figure 1: Individual and social incentives under the standard approach. 


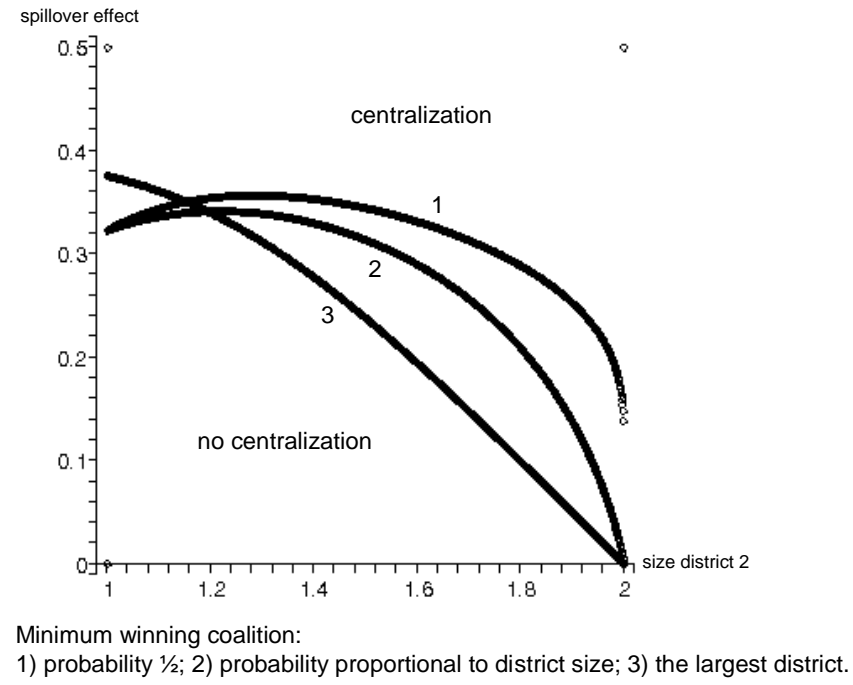

Figure 2: Individual incentives with a self-interested legislature (noncooperative). 


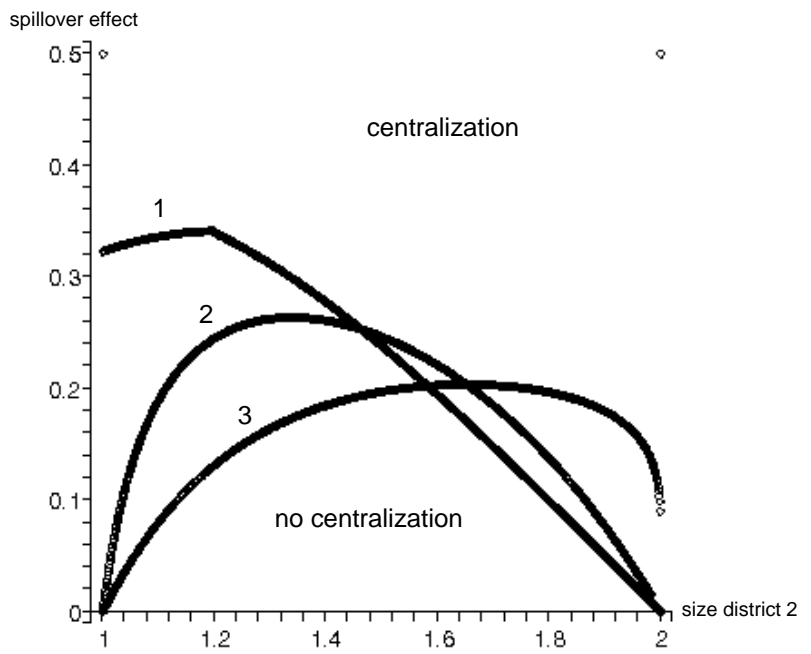

1) self-interested legislature (noncooperative); 2) benevolent legislature; 3 ) standard.

Figure 3: Comparison of individual incentives. 